\title{
Single Nanoparticle Ion Trap (SNIT): A Novel Tool for Studying in-situ Dynamics of Single Nanoparticles
}

\author{
Sung Cheol Seo, Seung Kyun Hong, and Doo Wan Boo*

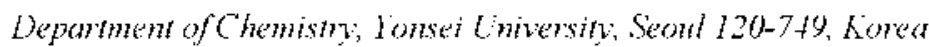 \\ Received December 28,2002
}

\begin{abstract}
The development of high perlomance single nanoparticle ion trap (SNT) apparatus lor studying in-sin dy namics of single nanoparticles in controlled enviromments is described. The perlomanec ol sNT apparatus has been evaluated for $500 \mathrm{~mm} \mathrm{SiO}_{2}$ particles. The mass resolution of $\sim 100 \mathrm{ppm}$ and the capability of varying the charge states independently have heen demonstrated.
\end{abstract}

Key Words : Single nanoparticle, Ion trap, in-situ dỵnamics, Mass analýsis

\section{Introduction}

In recent years considerable interest has arisen in the sludy of cheinical reactions and nanoparticles at the single molecule level in various en ironments. 'The single molecule manipulation techniques ofien cmployed are based on scanning probc microscopy (SPM). sucl as AFM. STM. near-field scamning optical microscopy (NSOM) and their variations.- These SPM-based studies have advanced greatly our understanding of the chemical processes and propertics of nanoparticles on surfaces." Howerer. these techniques pose complexities in deducing the exact origins of molecular processes and nanoparticle properties due to the complicated nature of tip-sample and sample-surface interactions.

To overcome the intrinsic difficultics of the SPM-based methods. we developed a new single molccule manipulation method that can isolate single molccules and nanoparticles under controlled enironments in the gas phase (in vacuum and ambient pressure) and monitor in sitt (he propertics and reaclions of single molecules and nanoparticles. The basic unit is based on the Paul ion trap.' which is often used in comentional ion trap mass spectrometers. ${ }^{5}$ In our apparatus. called a single nanoparticle ion trap (SNIT). the trap structure and delccion scheme are greally modificd from the comentional Paul trap for the efficicnt isolation and ultrasensitive delection of single micro- and nano-sized particles. In this paper. we report the development of a single nanoparticle ion trap (SNIT) apparatus aimed at performing speciroscopy on single mass- and charge-selecied molecules and nanoparticles. and its first application to single $500 \mathrm{~mm}$ $\mathrm{SiO}$ = ranoparticles.

\section{Experimental Details}

The SNIT apparatus is composed of two cap clectrodes and onc surrounding octapole. Which is different from the comentional Paul I rap (consisting of two cap clectrodes and

\footnotetext{
*lo whom correspondenes should be addressed. Iel: $+82-2-$ 2123-2632, lax: +82-2-364-7050: L-mail: dubootalchemy. yonsei.ac kr
}

one ring electrode). Due to the open structure of SNIT, our apparatus has the advantages of casy access to the trap center and high detection efficiency for low level scatlering and fluorescence light. A home-made AC high voltage supply (4 $\mathrm{kV}_{\mathrm{p}-\mathrm{p}}$ max.. $0.1 \mathrm{H} /-50 \mathrm{kH} /$ ) connecled to two cap clectrodes is used to generate effective hamonic potential for trapping charged nanoparticles. The DC-biased octapoles are used to compensate for the gravitational force and manipulate the horizontal and vertical locations of nanoparticles inside the trap.

The trapped nanoparticles are irradiated by a home-made diode laser $(675 \mathrm{~nm} .5 \mathrm{~mW})$ witl a gaussian beam profile. The scallered light is collected by objective lens arrays in threc orthogonal directions and then detected by wo CCD cameras and one avalanche photodiode (APD) detector (Hamanatsu. model $\mathrm{C} 54(0)-01)$. The ion trajectorics monitored at the side and bottom of the trap by two CCD cameras are used to optimize the motions of trapped particles. The outpul from the APD detector is preanplificd $(\times 100)$ and fed into a digital oscilloscope to determine the time crolution of scatiered light intensity. Subsequently. the time-dependent signals are com erted to the power spectrum in the frequency domain by using a fast Fouricr 1ransfonn (FFT) roulinc. The secular frequencies and their higher hannonic frequencies ir the spectrum are then assigned to the corresponding secular motions. Combined with the predetemined trap geometry and potential parameters. 1he sccular frequencies are used to detennine the mass-to-charge (M/Q) ratio according to the relationslip between the sccular frequencies and $\mathrm{M} / \mathrm{Q}$ values:

$$
H / Q=\sqrt{2} r_{c 1} / z_{l 1}^{2} \Omega\left(\omega_{z}\right.
$$

where $V_{i}$, and $\Omega 2$ are the amplitude and angular frequency of $\mathrm{AC}$ voltages. and $z_{i}$ is the distance between the trap center and the lyperbolic front surface of cap electrodes (sec ref. 7 for the details of principles).

To vary the cliarge states of trapped nanoparticles. a timegated clectron beam source consisting of a homemade clectron gun (containing a tungsten filament. cinzel lenses and deflectors). and a pulse generator with 100 us time 


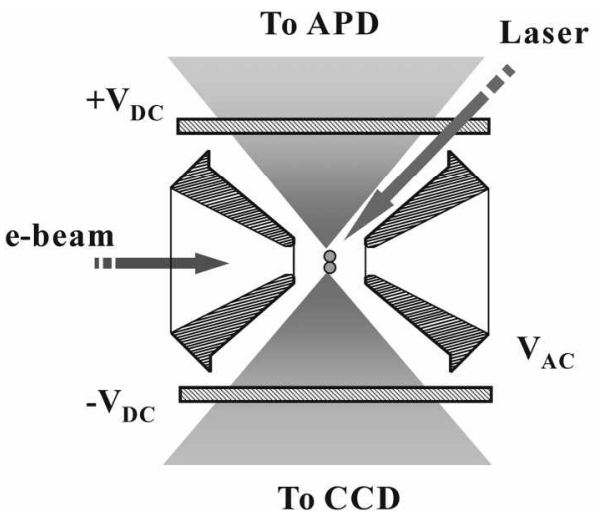

Figure 1. Schematic of the SNTT apparatus.

resolution was constructed and used for stepwise charging and discharging of nanoparticles. The secular frequencies at two different charge states. with the mass being maintained constant. were used to determme independently the mass and charge states. In particular, the changes in secular frequencies involving unit changes in charge states $(\Delta \mathrm{Q}=$ \pm 1 ) permit unambiguous assignment of absolute charge states of nanoparticles. Figure l shows the schematics of the constructed SNIT apparatus.

\section{Results and Discussion}

The standard $500 \mathrm{~nm} \mathrm{SiO}_{2}$ nanoparticles with the size distribution of $500 \pm 40 \mathrm{~nm}$ (Merck Co., SEM image inserted in Figure 2) were used to evaluate the performance of the SNIT apparatus and study in-situ the gas-surface reactions on single isolated $\mathrm{SiO}_{2}$ nanoparticles. The injection of $\mathrm{SiO}_{2}$ particles into the trap was accomplished by using a particle dropping method. In this method. He carrier gas ( I atm) passes through the microchannel $\mathrm{SiO}_{2}$ reservoir located at the top of trap. and expands via three pumping stages into

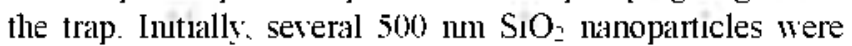
trapped and then ejected one by one by varying the DC potential of octapoles until a single stable $\mathrm{SIO}_{2}$ particle remained. The entire ejection processes were monitored by two CCD cameras.

Trapped nanoparticles tend to have high kinetic energies due to their large mass, so their energies needed to be

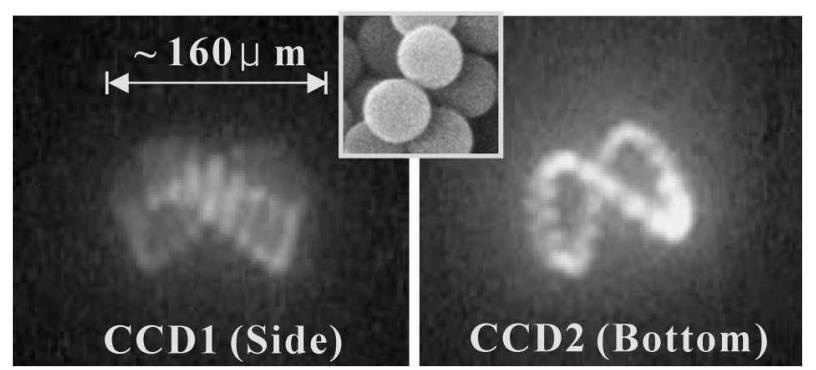

Figure 2. Ion trajectory images of single $500 \mathrm{~nm} \mathrm{SiO}_{2}$ particles captured by two CCD cameras at the side and bollom of the trap. The trap conditions are as following: $3095 \mathrm{~V}_{\mathrm{p}-\mathrm{p},}, 1568 \mathrm{~Hz}, 20.6 \mathrm{VDC}$. SFM image of 500 mu $\mathrm{SiO}_{2}$ jarticles (inset). dissipated to localize their motions near the trap center for better harmonic approximation. This goal was accomplished by introducing an instantaneous pressure jump inside the trap by a leak valve that damped the motions by collisional energy transfer to the background $\mathrm{He}$ gas. The ultumate pressure inside the trap was about $10^{-}$torr.

Figure 2 shows the trajectones of a single $500 \mathrm{~mm} \mathrm{SiO}=$ manoparticles captured sunultaneously at the side and bottom of the trap by two CCD cameras. The pattern of trajectory and stability of motion depend strongly on various trapping conditions. such as the trapping potentials and frequencies. $\mathrm{DC}$ bias of the octapole. etc. Very crucial to the technique is optinuzing the trapping conditions to mantain a stable secular motion of the particles to obtain the best mass resolution and accuracy of the SNIT apparatus. Under stable secular motion. the mass resolution and accuracy of SNIT apparatus is thought to depend mainly on the stability and accuracy of the electronics used in the experiment. The illustrated trajectories with $\sim 160 \mu \mathrm{m}$ size were obtained at $3095 \mathrm{~V}_{\text {p-j. }} .1568 \mathrm{~Hz} .20 .6 \mathrm{~V}_{\mathrm{L} \text {. }}$ octapole bias.

Figure 3 illustrates the stepwise charging and discharging processes of a single positively charged $500 \mathrm{~lm} \mathrm{SiO}_{2}$ particle by the time-gated electron beam $(500 \mathrm{eV}$ energy). The secular frequencies and charge states reman constant withun the resolution of the measurement electroncs employed $(\sim 100 \mathrm{ppm})$. changing only when the trapped particles are interrogated with an electron beam. The charge state of positively charged nanoparticles tends to increase via multielectron emission by high energy electron bombardment. and in rare events (for instance. No. 72 in Figure 3) decrease via electron attachment of slow secondary electrons. Since the unfavorable electron attachment by slow electrons occurs predomunantly via a single electron event involving the changes of charge states by unt charge $(+Q / e)$, the differences in secular frequencies for charging steps are set to be integer multiples of the differences in secular frequencies of the electron attachment step (No. 72). The absolute mass and charge states of nanoparticles are determined separately on thus basis. In thus particular case in the present study, the mass of the $500 \mathrm{~mm} \mathrm{SiO}$ - particle was determined to be $1.0618( \pm 0.0001) \times 10^{-16} \mathrm{~kg}$ in close proximity of the previous measurement $\left(1.3 \times 10^{-16 i} \mathrm{~kg}\right) .^{6 i .8}$ We believe that the

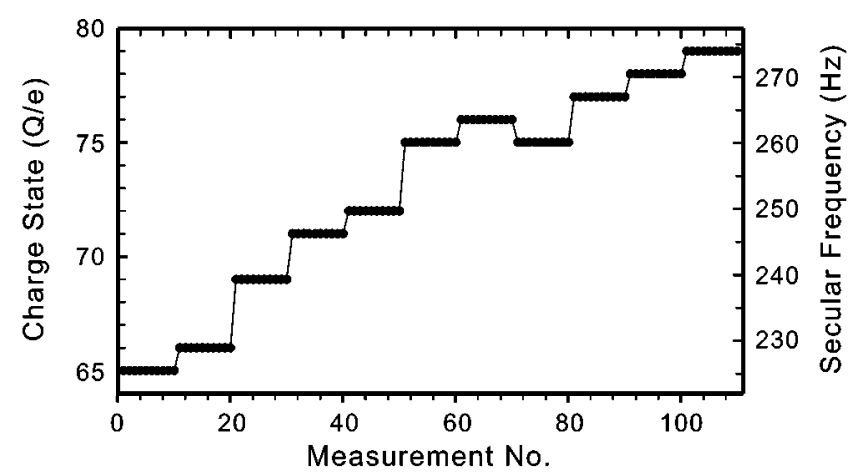

Figure 3. Slepifisc charging and discharging of single positively charged $\mathrm{SiO}_{2}$ particle by time-gated electron bom. Lilectron beam eneray was $500 \mathrm{eV}$. 
discrepancy in the two values is due to the size distribution of $\mathrm{SiO}_{2}$ nanoparticles. not the inaccuracy of the SNIT apparatus.

The size range for nanoparticles trapped by our SNIT apparatus was $100 \mathrm{~nm}-50 \mu \mathrm{m}$, and the achieved mass resolution was $\sim 100 \mathrm{ppm}$. With the incorporation of a fluorescence detection method, high frequency $\mathrm{AC}$ supply (up to $\mathrm{l} \mathrm{MHz}$ ), and high accuracy measurement instruments, the size range of 1 num-50 $\mu \mathrm{m}$ and mass resolution of 1 ppm can be achieved. The current SNIT apparatus can be used to study in-sint the growth dynamics of carbon nanotubes on single catalytic nanoparticles. and also the fluorescence behavior of single quantum dot-silver nanoparticle composites in controlled enr iromment. Such work is in progress.

In summary the present study describes the development of a lugh perfonmance single nanoparticle ion trap apparatus to study the in-sint dynamics of single nanoparticles and eventually single molecules in controlled environments. We live demonstrated the capability to trap $500 \mathrm{~lm} \mathrm{SiO}$. particles. varying independently the charge states of trapped manoparticles, and determining the mass within $\sim 100 \mathrm{ppm}$.

Acknow ledgement. This work is supported by grant No. 1999-2-121-004-5 from the Basic Research Program of the
Korea Science \& Engineening Foundation.

\section{References}

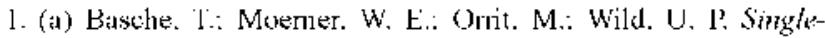
Holecule Optical Detection. Imaging and Spectroscopl. VCH Verlagsgesellschatt mbH: Weinheim. 1997. (b) Rigler. R.: Orrit, M.: Basche. T. Single Holecule Spectroscopyr Spritger-Verlag: Berlin. 2001.

2. (a) Bonnel1. D. Scoming I'rote Michoscopy and Spectroscepp Thenn, Techiques, and Apptications. $2^{\mathrm{th}}$ Ed.: Wiley-VCH: Neu York, 2001. (b) Mocmer. W. Г.: Orrit. M. Science 1999. 283, 1670. (c) Gimzenski. J. K. Joachitn. C. Sicience 1999. 283. 1683.

3. (a) Weiss. S. Science 1999, 283, 1676. (b) Mehta, A. D.: Rict. M.: Spudich. J. A.: Smith. D. A.: Simmens. R. M. Science 1999. 283. 1689

4. (a) Paul. W. Rev .Hod. Phys, 1990. 62. 531. (b) Amold. S.: Folan. I. M. Rev Sici. Instrum. 1986. 57, 2250.

5. March, R. Г.: Todd, J. Г. J. Proctical Lspects of lon Trap Wass Spectrometry fol I, IF, CRC Press: New York, 1995.

6. Schlemmer. S.: Illemann. J.: Wellert. S.: Gerlich. D. J. Appl. Whrs. 2001. 90.5410 .

7. Winter. H.: Ortjohamn. H. W. Am. J. Phys. 1991. 59.807.

8. The error of mass determitation $(-0.0001)$ correspond to $+1 \sigma$ (standard deviation) for 110 measurements on the same $\mathrm{SiO}_{2}$ particle for this particular case. Similar error ranges were obtained for over 50 diflerent $\mathrm{SiO}_{2}$ particles with diflerent mass. 